\title{
Urban Noise: A Case Study in Dire-Dawa City, Ethiopia
}

\author{
Belay Sitotaw Goshu, Hailemariam Mamo, Solomon Zerihun
}

Department of Physics and Biology, Dire-Dawa University, Dire-Dawa, Ethiopia

\section{Email address:}

belaysitotaw@gmail.com (B. S. Goshu), hailmariammamo05@gmail.com (H. Mamo), solx16@gmail.com (S. Zerihun)

\section{To cite this article:}

Belay Sitotaw Goshu, Hailemariam Mamo, Solomon Zerihun. Urban Noise: A Case Study in Dire-Dawa City, Ethiopia. European Journal of Biophysics. Vol. 5, No. 1, 2017, pp. 17-26. doi: 10.11648/j.ejb.20170501.13

Received: December 20, 2016; Accepted: January 6, 2017; Published: March 2, 2017

\begin{abstract}
Urban noise pollution is one of the problems of the people who live in urban area and it is a cause of health and social problem. The main purpose of this work is to identify the major cause of the pollution and to determine the noise pollution levels in the city. A study was conducted on the main roads of Dire-Dawa city using digital Sound Level Meter (SLM). A case study was illustrated by applying standardized methods to find noise pollution in the city. It was found that the noise levels in overall city were very high and above the permissible limits. The result revealed that in the selected area of hospitals, the noise pollution is 103.68 and $104.27 \mathrm{~dB}$ during morning and in afternoon respectively. In general, the average values of the noise levels throughout the study area were between 45 and $95 \mathrm{~dB}$ in places of bargele and Medirbabur respectively.
\end{abstract}

Keywords: Noise Level, Noise Pollution, Sound Level Meter

\section{Introduction}

Noise is unwanted sound. Sound is the form of energy which is emitted by a vibrating body and on reaching the ear causes the sensation of hearing through nerves. Sounds produced by vibrating bodies are not audible. The frequencies of limits of audibility are from 20 to $20000 \mathrm{~Hz}$. The sources of noise are traffic noise such as vehicles, train, plane, loudspeaker, music shop, etc.

A noise problem generally consists of three interrelated elements, the sources, and receiver and transmission paths. The transmission path is usually the atmosphere through which the sound is propagated, but it can include the structure materials of any building materials. Noise has gradually and steadily increased as civilization advanced and is considered among the most pervasive and frustrating sources of everyday annoyance. Noise is considered an environmental pollutant because of the danger it poses to health and the way it affects our well being and quality of life. It differs from any other forms of pollution since it is transient; once the noise stops, the environment is free of it. It comprises the fourth pollution area after air, water and soil pollution. Noise pollution which has arisen with the development in technology is one of the most important issues nowadays [1].
One of the serious and the most often unnoticed issues in environmental pollution is traffic noise [2]. In many countries, road traffic is the most widespread sources of noise. Recent evidence suggests that noise pollution may be a contributing factor to high blood pressure, anxiety and nervousness [3]. The traffic noise is generated from the engine and from frictional contact between the vehicle and ground and air [4]. Noise generated from the traffic depends on traffic volume of road surface. The road traffic noise level is the aggregation of the individual vehicle noise. Each vehicle generates different tone of noises from its source such as engine, contact tyres and road, exhaust, fan, air intake [3].

Noise is seen as a normal phenomenon. There is no any action plan considered seriously to protect the citizens from such hazard by the government of the country. But this does not mean, the impacts of noise is not well understood. May be, this is not their priority agenda for the time being for the city administration. However, the citizens suffer from such unwanted sound. Urbanization and associated growth in mobility and industrialization have resulted in the intensification of noise in densely populated areas causing an increase in noise exposure. As the population increases in an urban area, industrial activities also increase to meet people's needs; this result increased the noise levels [5].

Noise Mapping or measuring makes the government aware and hence enables them to take suitable measures to mitigate 
it, thus leading to proper town planning [6]. Therefore it is very important to measure the level of the noise in the city and to create awareness to the citizens. Even if it is a transient pollutant, the level of understanding helps to control the pollution. This will help the citizens to realize the level of the noise that they are exposed and to develop the mechanism for tackling the problem.

It is well known that sound propagation is affected by different. Those factors are: types of sources, distance from the source, atmospheric absorption, wind, temperature and its gradient, obstacles such as barriers, ground absorptions, reflections, humidity and precipitation. To measure or record the noise levels we have to take account all those factors. But in this work we mainly focus on the average noise, noise level pollution and equivalent continuous emission of noise levels.

The key aim of this work is to find the equivalent intensity of noise and identify which areas of the city is more polluted by the noise. It also intended to ascertain the extent to which people in the city perceive noise to be a problem and identify which noise sources.

The second section describes the background information of Dire-Dawa city. The third section describes the methods and data collection. The fourth section describes the result and discussion by comparing with the results with that World health organization data and the last section describes the conclusion.

\section{Background of the Study Area}

Environmental noise pollution continues to pose a significant threat to human health and the quality of life for millions of people worldwide. Urbanization and associated growth in mobility and industrialization have resulted in the intensification of noise in densely populated areas causing an increase in noise exposure. As the population increases in an urban area, industrial activities also increase to meet people's needs. This results in increased noise levels. In order to understand what noise and thus noise pollution is, it is first vital to understand what sound is, how it is produced and how it consequently becomes noise.

Dire Dawa is the second largest city in Ethiopia next to the capital Addis Ababa. It is found in latitude of 9, 5833 $\left(934^{\prime} 59.988^{\prime \prime} \mathrm{N}\right)$ and longitude of 41,8667 (4152'0.120"E) and with average altitude of $1,221 \mathrm{~m}$ above sea level. Currently, its estimated population size is about 395,000 . It is a desert city where almost all ethnic groups found in Ethiopia have been living peacefully. There are many commercial activities, industrial sites, institutional, recreational, residential areas. There are about 6,000 three wheel vehicles (bajaj and forces), thousandth of automobiles and trucks within the city. Dire-Dawa is one the town which is near to Djibouti port and there is a railway which connects two cities in land. There is also one nation and international air port which connects the city with abroad. There is at least one mosque and church in every village that generates noise pollution which arise from loudspeakers, salesman to advertise their wares, highly amplified music from record shop. The nature of the roads is found in Dire Dawa administration is asphalt, concrete types and the rest of the road was constructed by stone commonly called cobblestone stones.

\section{Methods and Data Collection}

A digital sound level meter whose mark is Az8928 used to measure the sound intensity level which range from 40 to 130 $\mathrm{dB}$ sound level meter. The device measured with $\pm 2 \mathrm{~dB}$ accuracy. It is commonly used for noise pollution in urban area for quantification of different kinds of sound level.

Sampling locations considered for noise pollution analysis in Dire Dawa city are hospital zones educational zone, church and mosque zones, hotel and recreational areas, offices and working areas, residence and market areas. The sound level around these areas expected to be optimum for normal and healthy communication and working conditions. These areas are populous in which various noises disturb the working conditions.

Data collection is done by measuring the noise level in the main line of the city road for two months. The data is collected in every location is taken for two specific times of the morning and afternoon as it was done in [7] and they are: Morning from 9:00 to 11:00 AM in some specific areas and Afternoon from 18:00 to 20:00 the same areas. We choose data collection time in some cases depending on the activities held on there.

We grouped the places on the type of activities provide for the society. We classified the places into five groups to analyze the data. The zones are Hotels, Churches or Mosques, Offices, Hospitals and Schools or College or University. This classifications based on the amount of noise emissions in such places have a great impacts on human being.

As [8] and [9] had investigated the road traffic noise for two months of the year 2016; we collected for two months of the year 2016 at different location of Dire-Dawa city. The highest traffic noise levels will occur around the main line of the city road. The traffic is busy everywhere of the city. This is maintained to avoid any interferences of noise. The instrument was fluctuating due to different sources of noise when they are approaching. Therefore we recorded data after every 5 seconds for twelve times. These values were used to find the average noise in those particular places. As we see in Tables 1, 2, 3, 4, 5 and 6, recording were taken for two hours in the morning and afternoon for two months in 2016. We used these data to find the equivalent noise intensity in the given time intervals, $\mathrm{L}_{\text {eq }}$ is the equivalent continuous equal energy level; and can be applied to any fluctuating Noise Level. It is given by [6].

$$
L_{e q}, T=10 \log \left(\frac{1}{n} \sum_{i=1}^{n} 10^{L_{i} / 10}\right)
$$

Where $L_{e q}$ is the equivalent noise levels observed in time interval $T$ and $n=n^{\text {th }}$ duration of measurement.

Equation 1 is to use an integrating noise level meter 
averaging over the time interval. The sum of the total energy over some time period gives a level equivalent to the averaging sound energy over that period. Thus, $L_{e q}, T$ is the energy average equivalent level of the weighted sound over period $T . L_{e q}, T$ should be used to measure continuing sounds, such as road traffic noise or types or more or less continuous industrial noise [17].

Total annoyance caused by noise level was estimated using Noise Pollution (NP) level index can be calculated by the expressions given by (LNP) [6].

$$
L N P=L_{e q} \times 2.56 \delta_{s t d}
$$

We use statistical analysis techniques. It was taken to analyze the data and to get significant differences between the measurements of noise level during morning and night times. We also used the measurements to analyze the data and understand which area of the city will be affected on this disturbance.

Noise has become an important element of environmental pollution as a result of increasing industry and urbanization. Though noise has many negative effects on people's health it is still not regarded as a risk in our society. However it is obvious that the best solution to protect ourselves from the negative effects of noise is to monitor the source of the noise. This issue must be focused on schools, workplaces, hospitals and health institutions and residential areas. The sensitivity of the society should be raised.

\section{Results and Discussions}

Noise levels within the study area were observed on field measurements for two months in the morning and afternoon times. Traffic noise near to the main roads of Dire-Dawa city was recorded to find the equivalent intensity of noise and to identify which part of the city is severely affected by the noise. In this work we identified the major source of pollution. The major sources of noise we observed during recording were bajaj, forces, truck vehicles, microphones or amplifiers and music from hotels.

\subsection{Average Noise Levels Near Hospitals}

In this study recording were taken in seven hospitals in Dire-Dawa city including public hospitals, private and one health center. Figure 1 shows that the average noise measured for eight days during morning from 9:00 to 11:00 AM and in the afternoon from 18:00 to 20:00 PM. The major sources are vehicles like bajaj and forces. The minimum average noise recorded near to Dire health center $56.7 \mathrm{~dB}$ in the afternoon; whereas the peak noise was recorded in the afternoon near to Delchora Hospital has a magnitude of $86.91 \mathrm{~dB}$. The results we observed during the morning and night are above the recommended limit set by [4]. The results confirm that in all cases near to hospitals the magnitudes of noise levels are high. This will not give comfort for patients in the hospitals, which aggravated their health problems. In most of the areas the noise levels is exorbitant with more than $80 \mathrm{~dB}$ average prevailing across the city during both morning and afternoon. This is mainly attributed towards congested traffic area and unplanned construction of hospitals. Most of hospitals were constructed near to the main lines of traffic and they are affected severely by noise pollution. It is considered as the best indicator of physiological and psychological impact on patients and workers within these hospitals.

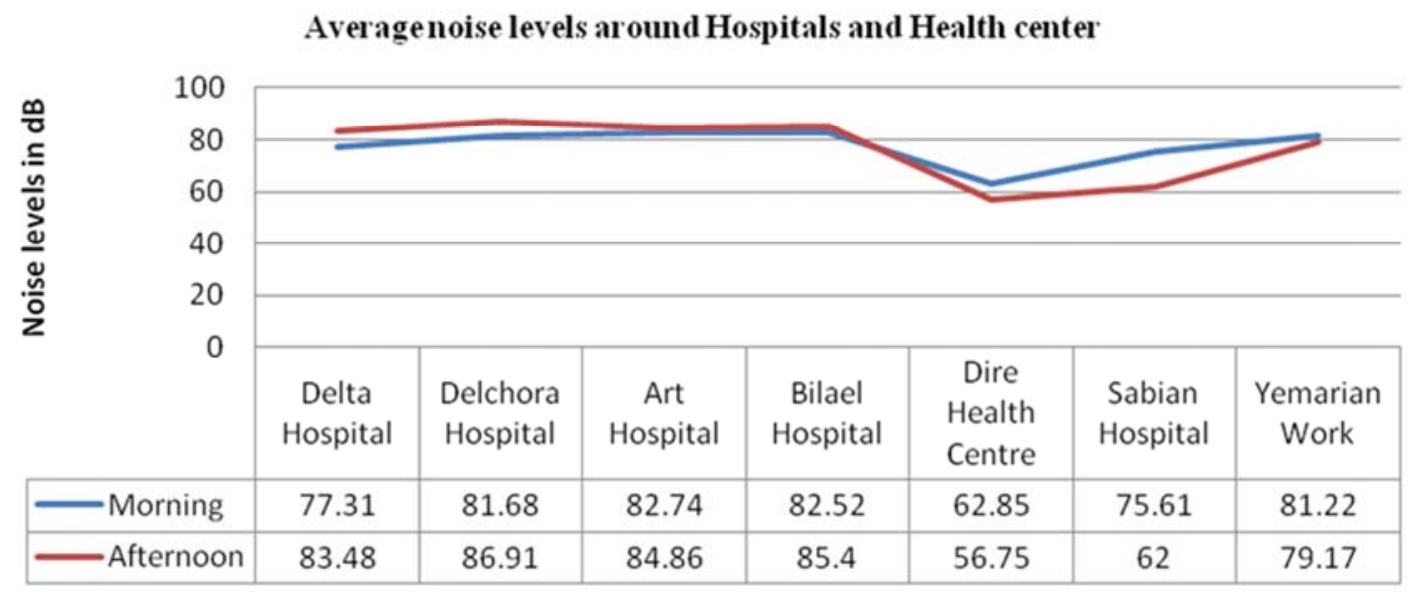

Figure 1. Average noise levels in $d B$ near to Hospitals and health center.

\subsection{Average Noise Levels Near to Education Centers}

Figure 2 shows the average noise levels recorded for nine days in both morning and afternoon. The minimum noise recorded in the afternoon from 15:00 to 17:00 PM near to Addis Hiwot High school. The peak noise recorded near to Comprehensive high school which has $82.4 \mathrm{~dB}$. There are high traffic flow vehicles in this particular place since it is the main gate of the city to enter and leave from the city. The result also confirms that in most of schools, the magnitude of noise is high during the morning than in the afternoon. Since all schools are located near to the main road of the city, they are exposed to noise disturbance in teaching learning processes. This may have direct impacts on the students' performance in their education carriers. It adversely affects cognitive task performance and impairs motivational parameters of students [10-14]. 


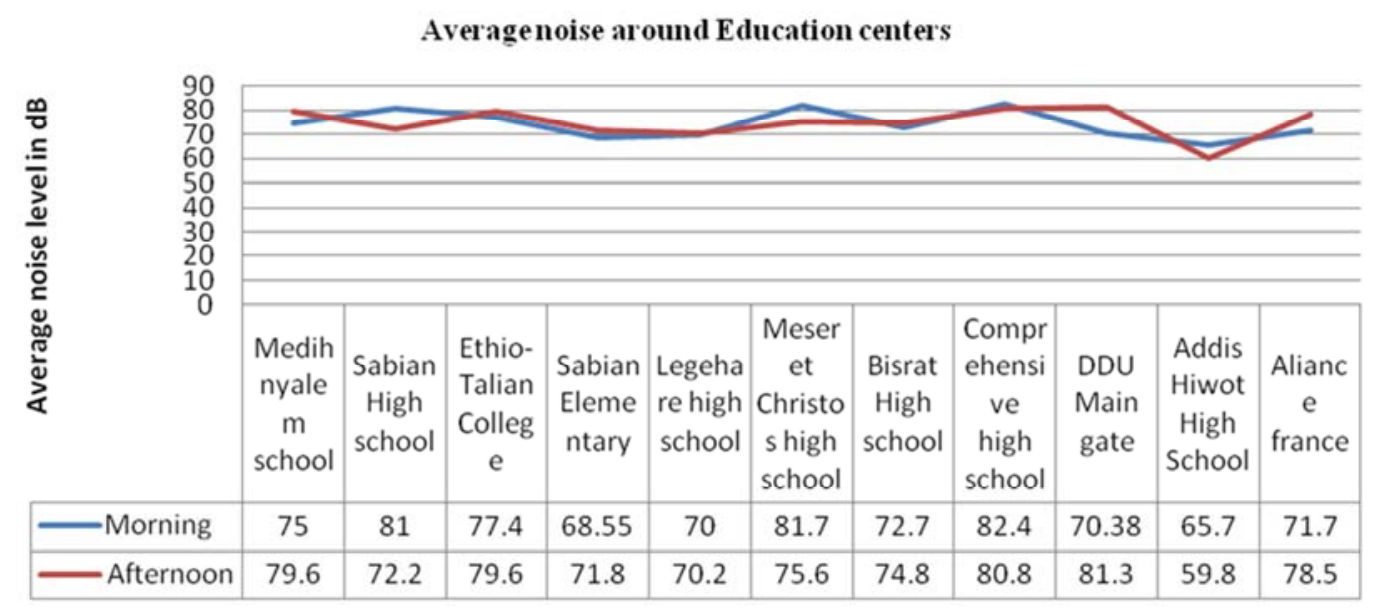

Figure 2. Average noise levels in $d B$ near to Education center.

\subsection{Average Noise Levels Near to Residence}

Figure 3 shows the average noise recorded near to the residence place in Dire-Dawa city. The result shows that Bargelle and Gendelome are a good sight for the residence relative to other residences places selected by the authors. The noise levels in both morning and afternoon in these two places are below $50 \mathrm{~dB}$. In most of residence places, the noise levels recorded in the afternoon is less than morning. But the places like shell, in both morning and afternoon, the noise levels recorded are $85.4 \mathrm{~dB}$ and $90.2 \mathrm{~dB}$ respectively. These two values above the limit of noise levels put by WHO. According to According to [15] study the effect of the noise levels on hearing impairment with the residential areas range should from 39-41 dB in less populated areas and 55$59 \mathrm{~dB}$ in dense populated areas. The values we obtained from the measurement are greater than the mentioned values. The result we obtained by [16] measured in other city of Nigeria is greater than the result we obtained in Dire Dawa city. Therefore, the recorded noise levels peoples leaves in environmental polluted area by noise. This may affects their health. The city expands every time because of the country development and the city is the industry corridor. Because of this the government should give attention on the noise pollution to improve the health of the citizens.

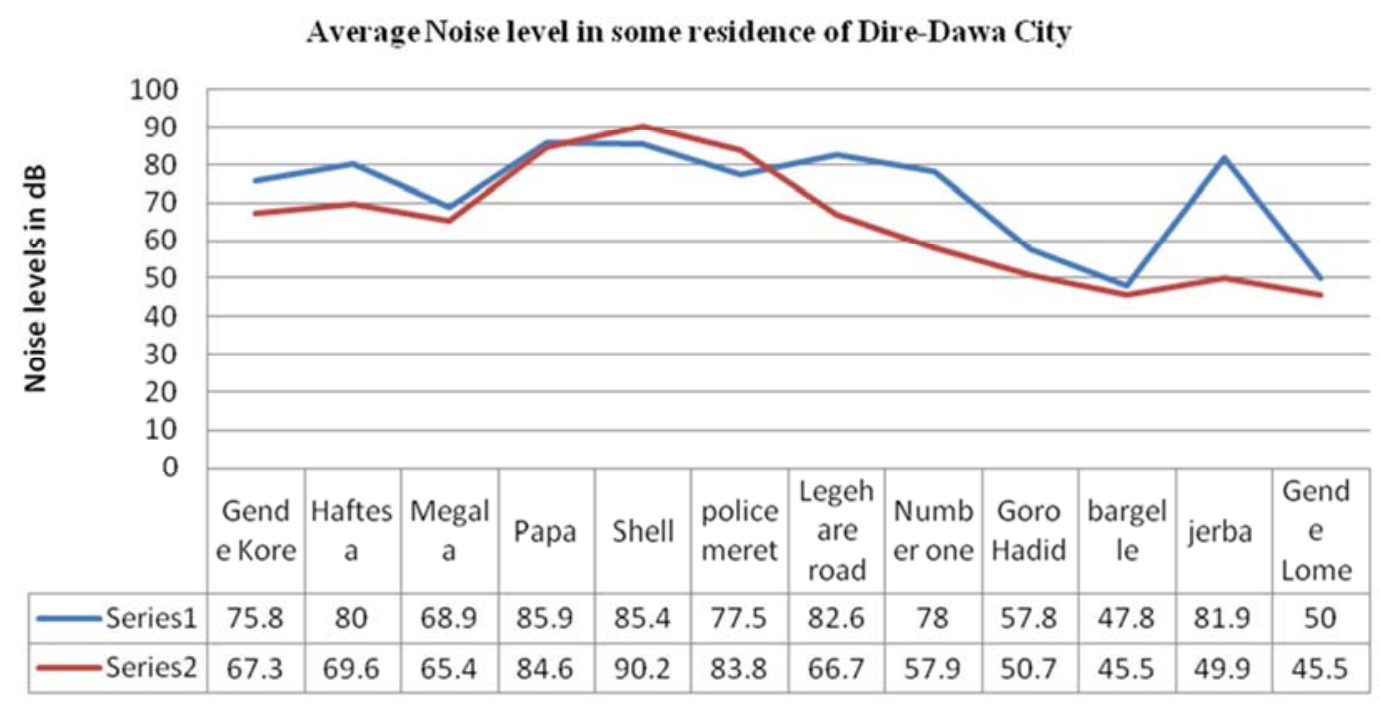

Figure 3. Average noise levels in $d B$ near to Residence.

\subsection{Average Noise Levels Near to the Office}

Figure 4 shows that the average noise levels recorded in some selected offices of the city. The result confirms that most of the offices located on the road side of the main line of the city. The performances of the employee are affected by the noise pollutions. This will decrease the performance of works. For instance, the offices which are found near to Midir Babur, they are highly affected by the traffic noises. The peak noise levels were recorded in this place both morning and in the afternoon were 94.68 and $89.79 \mathrm{~dB}$ respectively. There is also other place which has high noise levels were recorded near to the bus station in both morning and afternoon 85.75 and 88.53 $\mathrm{dB}$ respectively. This place especially is highly risk zone for both the workers and the residence around the bus station. The volume flow of buses, min-bus, bajaj and forces are relatively 
high. The city administration should work either to reduce the noise levels or change the place of the bus station to improve the working condition of both the workers and peoples who lived around the place.

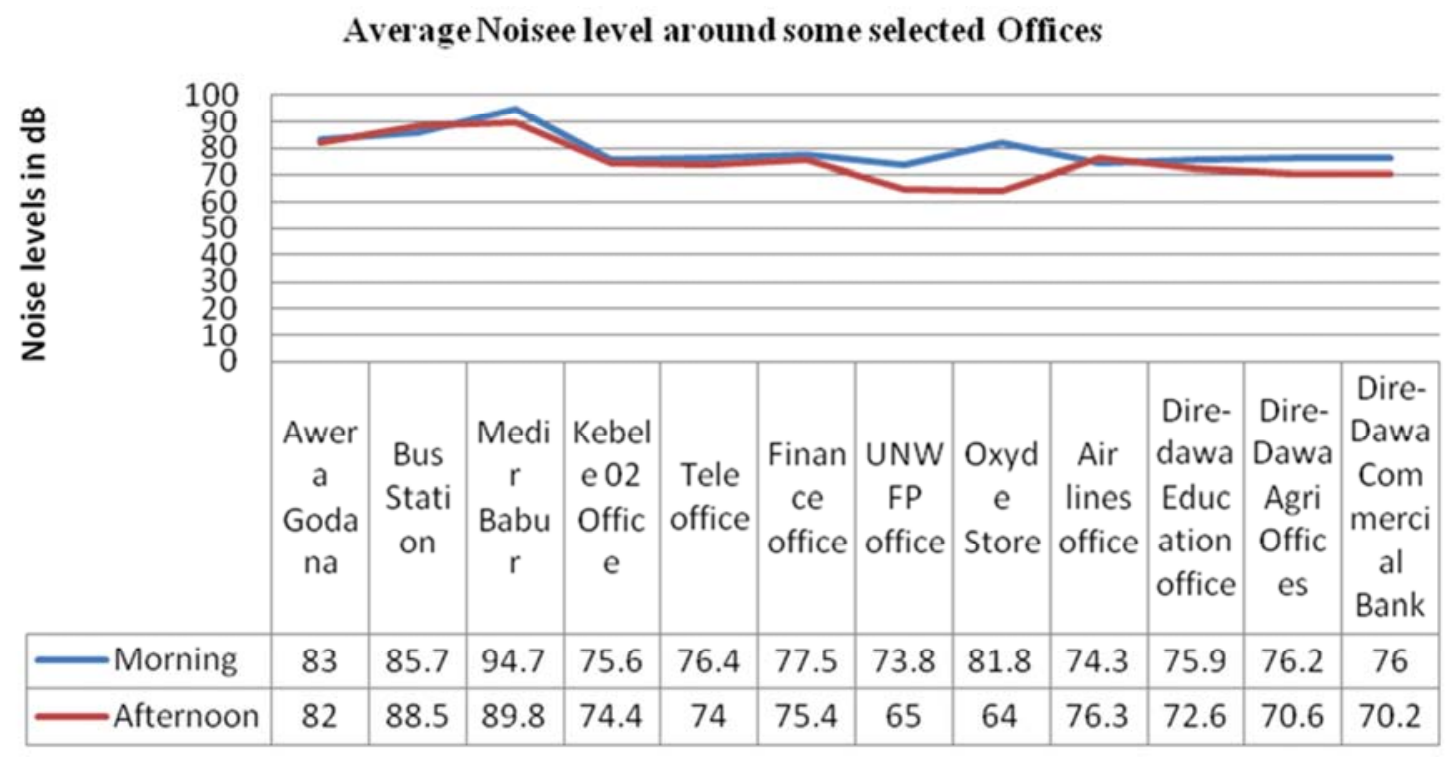

Figure 4. Average noise levels in $d B$ near to Offices.

\subsection{Average Noise Levels Near to Hotels}

Figure 5 shows the average noise levels near to some of hotels in Dire-Dawa city. The result confirms that the peak noise was recorded Mulugeta hotel in the afternoon, which is $90.6 \mathrm{~dB}$. Most of recorded results show that the average noise levels recorded were above $80 \mathrm{~dB}$ only in one hotel, the recorded noise was less relative to other. The result still shows that there is a big problem in noise pollution around all hotels. The city administration should work in line with the hotels managements and owners to reduce the pollution of levels of the noise especially the night time.

\section{Average Noisr level arouns selected Hotels and cafe}

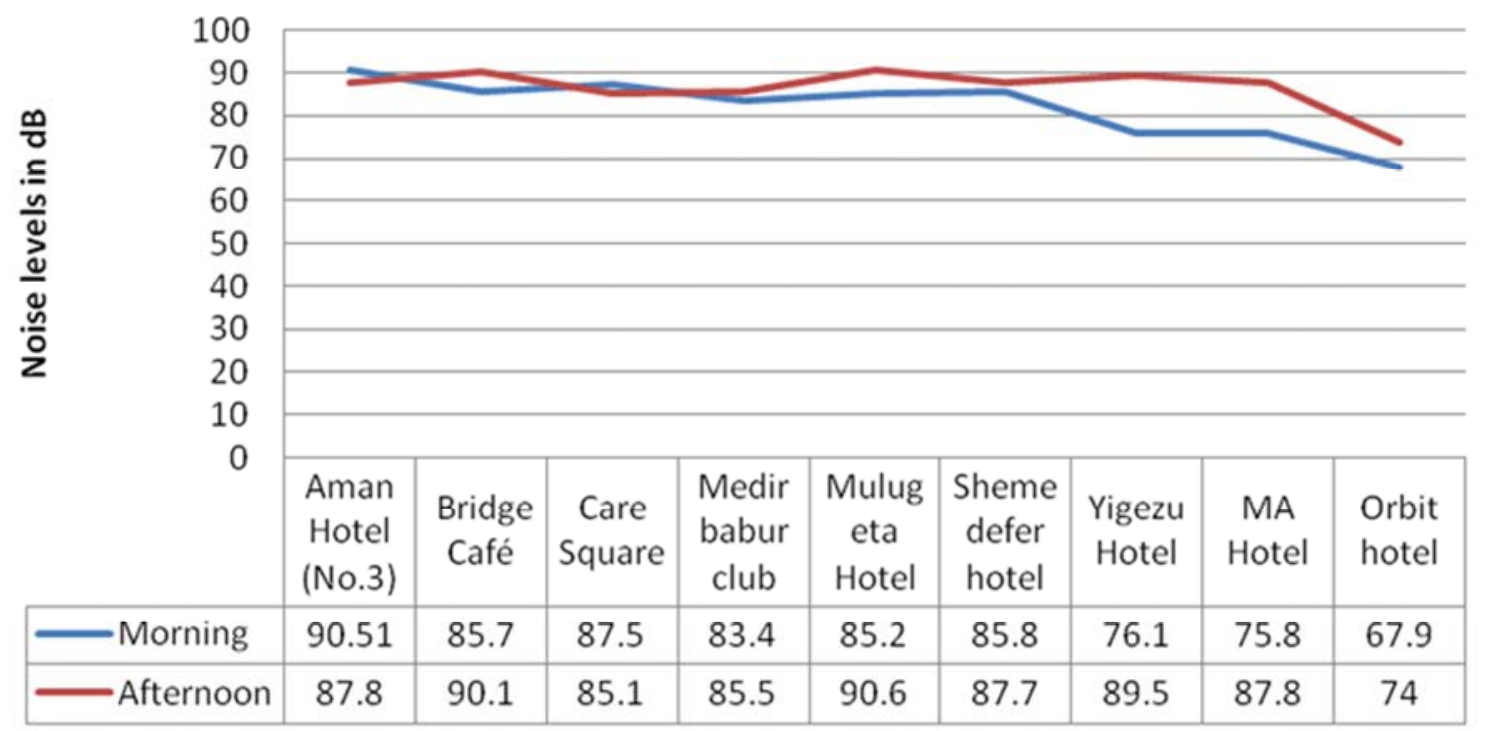

Figure 5. Average noise levels in $d B$ near to Hotels.

\subsection{Average Noise Levels Near to Churches and Mosques}

Figure 6 shows the average noise levels near to churches and mosques. This is another challenge of the city administration in reducing the disturbances levels of noise. The result shows that the peak noise levels were recorded near to Medihaneyalem church. The peak noise levels were
87.7 in the morning and $84 \mathrm{~dB}$ in the afternoon. Similarly the peak noise levels were recorded near to konel Mosque in the morning 80.3 and $80.4 \mathrm{~dB}$ in the afternoon. The least noise was recorded in Abuye Gebremenfes Kidus relative to others churches and mosques. The noise levels around churches and mosques are time dependents. 


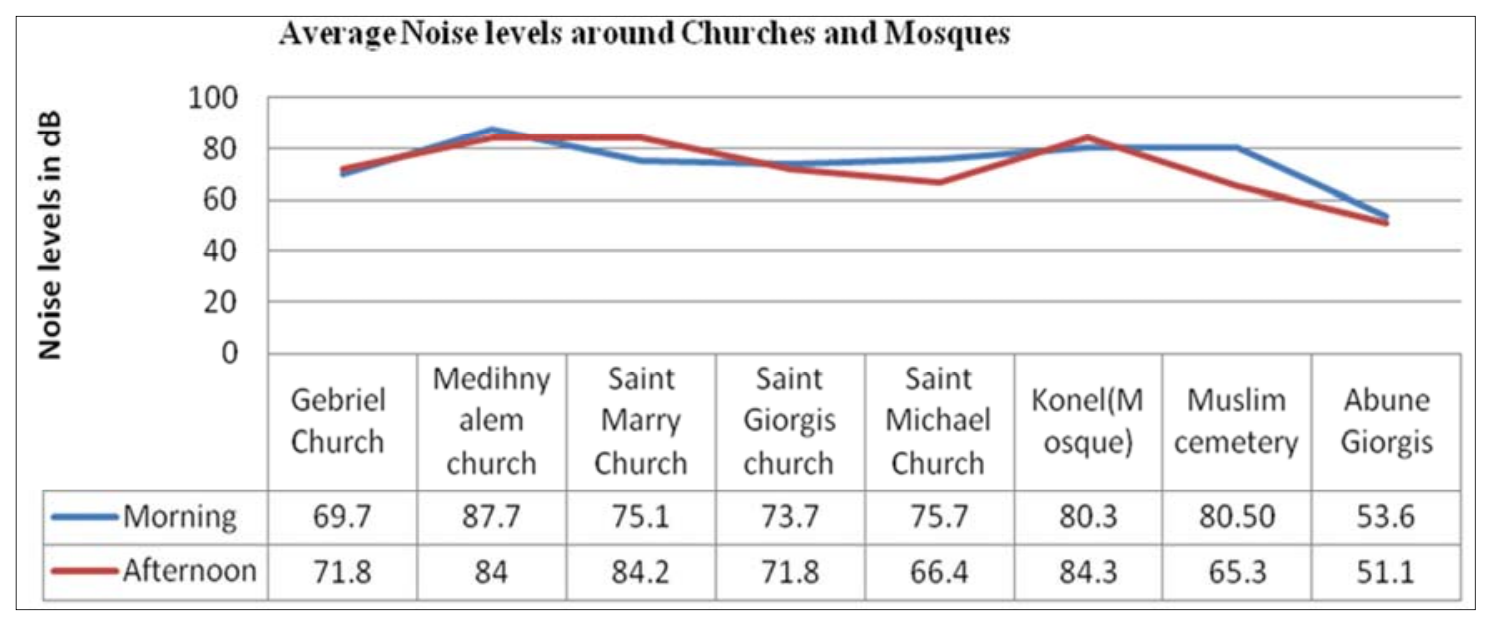

Figure 6. Average noise levels in $d B$ near to Churches and Mosques.

\subsection{The Noise Pollution Levels Around Hospitals}

As seen in Table 1 the maximum noise recorded near to Art Hospitals recorded was $98.2 \mathrm{~dB}$ in the afternoon time from 18:00 to 20:00 PM. The possibility of peak reading of the noise levels its close proximity of the main road of Sabian. This is due to the nature of the road and the high density of vehicle running on this road. There is also peak observation of noise near to Delchora hospitals. It has also peak deviation from the noise values. High noise pollution observed near to Delchora hospital has a value of 103.68 and $104.27 \mathrm{~dB}$ during morning and afternoon respectively. Delchora, Art, Bilael, Delta and Yemariamwerk hospitals do not give comfort for their patients. They are exposed to high noise pollution and increase their stress. The other three hospitals and health center relatively to Delchora Hospital, the degree of pollution is lesser. The mean noise level of Delchora Hospital is 81.68 $\pm 6.88 \mathrm{~dB}$ during morning and $86.91 \pm 5.47 \mathrm{~dB}$ in the afternoon. The minimum noise levels were recorded in morning and afternoon in Dire Health center whose mean deviations are $62.85 \pm 2.69 \mathrm{~dB}$ and $56.75 \pm 4.01 \mathrm{~dB}$ respectively.

Table 1. Noise levels in dB near to Hospitals, Noise range and Noise Pollution levels.

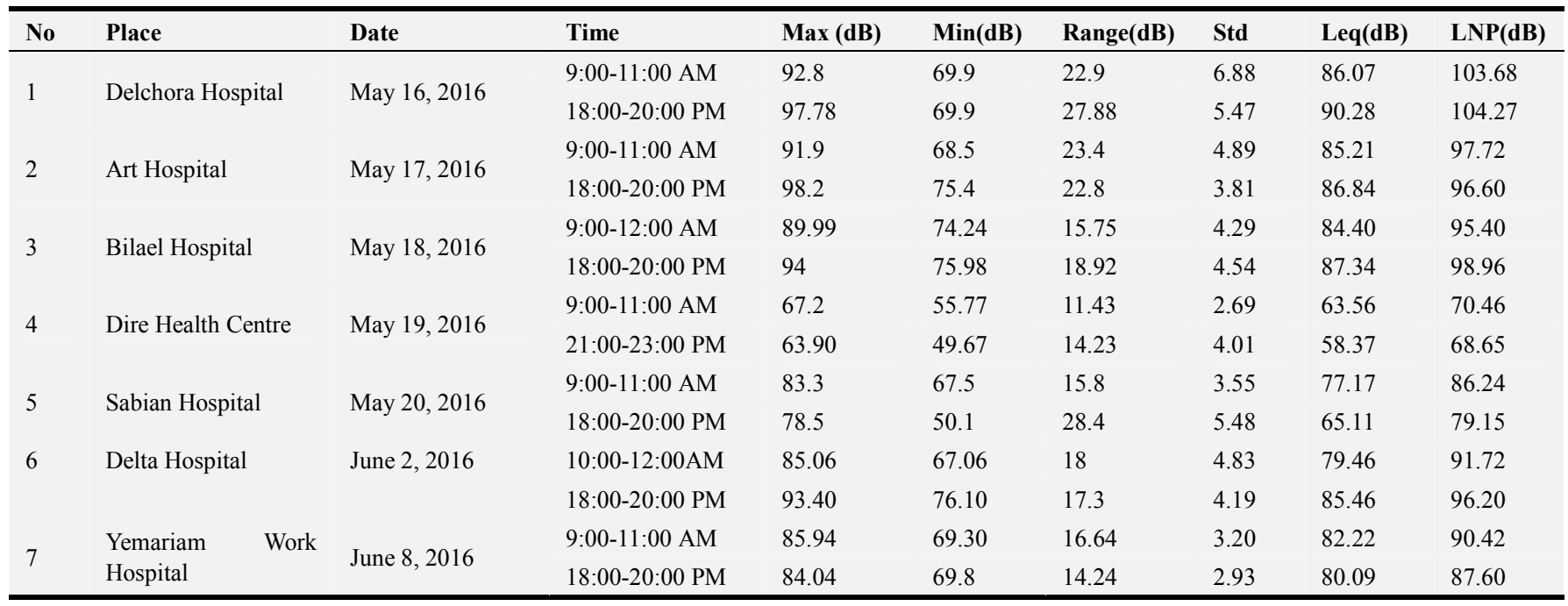

\subsection{The Noise Pollution Levels Around Churches and Mosques}

Table 2 describes the noise levels around churches and mosques. The maximum noise levels were observed in medihaneyalem church both morning and in the afternoon, saint marry church in the afternoon and sebategna mosque. This is due to their proximity to the main line of the road. As we from Table 2 the noise pollution were calculated from Eq. 2 show that, it is $86.6 \mathrm{~dB}$ with deviation of 3.2 around medihaneyalem church. There are also some churches and mosques which have high noise pollution shown in Table 2 . Least noise pollution was observed around Abune Giorgis in both morning and afternoon. This is due to less traffic and it is far from the main line of the road. 
Table 2. Noise Levels in $\mathrm{dB}$, Noise Range, the equivalent noise levels and noise pollution Levels in Church and Mosque in 2016.

\begin{tabular}{|c|c|c|c|c|c|c|c|c|c|}
\hline No & Place & Date & Time & $\operatorname{Max}(\mathrm{dB})$ & $\operatorname{Min}(d B)$ & Std & Leq(dB) & LNP(dB) & Range(dB) \\
\hline \multirow[t]{2}{*}{1} & \multirow[t]{2}{*}{ Saint Gabriel Church } & \multirow[t]{2}{*}{ May 23} & 6:00-8:00 Am & 83.4 & 59.28 & 5.26 & 72.32 & 85.79 & 24.12 \\
\hline & & & 18:00-20:00 PM & 79.12 & 62.5 & 5.37 & 74.26 & 88.01 & 16.62 \\
\hline \multirow[t]{2}{*}{2} & \multirow[t]{2}{*}{ Medhaniyalem Church } & \multirow[t]{2}{*}{ May 24} & $6: 00-8: 00 \mathrm{AM}$ & 91.23 & 73.5 & 3.20 & 88.70 & 96.90 & 17.73 \\
\hline & & & 18:00-20:00 PM & 85.4 & 79.9 & 0.55 & 84.09 & 85.61 & 5.5 \\
\hline \multirow[t]{2}{*}{3} & \multirow[t]{2}{*}{ Meseret Christos Church } & \multirow[t]{2}{*}{ May 29} & 10:00-12:00 AM & 72.80 & 58.30 & 3.38 & 68.59 & 77.24 & 14.5 \\
\hline & & & 18:00-20:00 Pm & 70.7 & 48.3 & 4.96 & 66.88 & 79.57 & 22.4 \\
\hline \multirow[t]{2}{*}{4} & \multirow[t]{2}{*}{ Saint Marry Church } & \multirow[t]{2}{*}{ May 30} & $6: 00-8: 00 \mathrm{AM}$ & 82.1 & 69.3 & 3.54 & 76.60 & 85.66 & 12.8 \\
\hline & & & 18:00-20:00 PM & 90.44 & 75.6 & 3.10 & 85.26 & 93.20 & 14.84 \\
\hline \multirow[t]{2}{*}{5} & \multirow[t]{2}{*}{ Saint Gorge Church } & \multirow[t]{2}{*}{ May 31} & $6: 00-8: 00 \mathrm{AM}$ & 83.7 & 58.5 & 4.84 & 75.97 & 88.37 & 25.52 \\
\hline & & & 18:00-20:00 PM & 85.50 & 65.88 & 3.76 & 73.58 & 83.20 & 19.62 \\
\hline \multirow[t]{2}{*}{6} & \multirow[t]{2}{*}{ Saint Michael Church } & \multirow[t]{2}{*}{ June 1} & 6:00-8:00 AM & 83.7 & 58.5 & 4.84 & 75.97 & 88.37 & 25.2 \\
\hline & & & 18:00-20:00 PM & 90.44 & 75.6 & 3.10 & 85.26 & 93.20 & 14.84 \\
\hline \multirow[t]{2}{*}{7} & \multirow[t]{2}{*}{ Holly Trinity Church } & \multirow[t]{2}{*}{ June 3} & $6: 00-8: 00 \mathrm{AM}$ & 88 & 78.8 & 2.37 & 84.0 & 90.47 & 15.9 \\
\hline & & & 18:00-20:00PM & 88.4 & 76.8 & 3.00 & 84.0 & 92.01 & 11.6 \\
\hline 8 & Sebategna Mosque & June 4 & 18:00-20:00 PM & 87.64 & 78.34 & 2.49 & 84.10 & 90.48 & 9.3 \\
\hline \multirow[t]{2}{*}{9} & \multirow[t]{2}{*}{ Konel Mosque } & \multirow[t]{2}{*}{ June 5} & 9:00-11:00 AM & 88.98 & 70.98 & 4.86 & 82.78 & 95.22 & 18 \\
\hline & & & 18:00-20:00 PM & 88.06 & 80.06 & 2.17 & 84.77 & 90.32 & 8 \\
\hline 10 & Muslim cemetery & June 6 & 18:00-20:00 PM & 88.30 & 70.50 & 2.94 & 81.34 & 88.87 & 17.8 \\
\hline \multirow[t]{2}{*}{11} & \multirow[t]{2}{*}{ Abune Gebremenfes Church } & \multirow[t]{2}{*}{ June 7} & $6: 00-8: 00 \mathrm{AM}$ & 63.1 & 41.36 & 4.37 & 55.15 & 66.32 & 21.74 \\
\hline & & & 17:00-19:00 PM & 60.31 & 45.7 & 4.28 & 53.44 & 64.41 & 14.61 \\
\hline
\end{tabular}

\subsection{The Noise Pollution Levels Around Education Centers}

Tables 3 describe the noise levels and the degree of pollution in each site of schools around Dire-Dawa city. The sites of schools are not good site for teaching learning processes. All are exposed to high noise pollution. DireDawa Comprehensive high school is severely exposed to high noise pollution. This is because of the comprehensive high school site. It is found on the main gate of Dire-Dawa. All types of vehicles were used to enter and leave DireDawa. The other reason is the nature of the road and traffic. The study showed that noise around the educational institutions mainly from vehicles disturbs the teaching learning and overall working environment. Similar research was done in Europe shows that in workers and children, that noise can adversely affect performance of cognitive tasks in most of education centers. Cognitive performance substantially deteriorates for more complex tasks. Reading, attention, problem solving and memorization are among the cognitive strongly affected by noise [17]. Noise pollution has been increased as the result of increased commercial activities, increase number of vehicles, bajaj and forces and populations near to education centers.

Table 3. Noise Levels in dB, Noise Range, the equivalent noise levels and noise pollution Levels near to University, College and High Schools in 2016.

\begin{tabular}{|c|c|c|c|c|c|c|c|c|c|}
\hline No & Place & Date & Time & $\operatorname{Max}(d B)$ & $\operatorname{Min}(d B)$ & Std & Leq(dB) & $\operatorname{LNP}(d B)$ & Range(dB) \\
\hline \multirow{2}{*}{1} & \multirow{2}{*}{ Main gate of DDU } & \multirow{2}{*}{ May 12} & 9:00-11:00 AM & 82.89 & 58.24 & 6.58 & 75.28 & 92.13 & 24.7 \\
\hline & & & 15:00-17:00 PM & 99.01 & 65.4 & 6.10 & 87.6 & 103.22 & 33.6 \\
\hline \multirow{2}{*}{2} & \multirow{2}{*}{ Medihaneyalem school } & \multirow{2}{*}{ May 13} & 9:00-11:00 AM & 80.7 & 62.5 & 3.46 & 76.28 & 85.14 & 18.2 \\
\hline & & & 15:00-17:00 PM & 84.2 & 74.8 & 1.97 & 80.03 & 85.06 & 9.4 \\
\hline \multirow{2}{*}{3} & \multirow{2}{*}{ Sabian High School } & \multirow{2}{*}{ May 14} & 9:00-11:00 AM & 86.78 & 75.18 & 2.74 & 81.93 & 88.93 & 11.6 \\
\hline & & & $15: 00-17: 00 \mathrm{PM}$ & 79.76 & 64.5 & 3.97 & 74.07 & 84.24 & 15.3 \\
\hline \multirow{2}{*}{4} & \multirow{2}{*}{ Ethio-Italian College } & \multirow{2}{*}{ May 15} & 9:00-11:00 AM & 85.34 & 61.4 & 3.86 & 79.14 & 89.02 & 23.9 \\
\hline & & & 15:00-17:00 PM & 83.68 & 69.1 & 2.49 & 80.31 & 86.69 & 14.6 \\
\hline \multirow{2}{*}{5} & \multirow{2}{*}{ Sabian No 2} & \multirow{2}{*}{ May 16} & 9:00-11:00 AM & 75.84 & 53.4 & 3.81 & 70.11 & 79.87 & 22.4 \\
\hline & & & 15:00-17:00 PM & 79.28 & 62.5 & 2.67 & 72.81 & 79.64 & 16.8 \\
\hline \multirow{2}{*}{6} & \multirow{2}{*}{ Legehare High school } & \multirow{2}{*}{ May 17} & 9:00-11:00 AM & 74.2 & 60.5 & 2.92 & 70.71 & 78.19 & 13.7 \\
\hline & & & 15:00-17:00 PM & 74.48 & 60.5 & 2.91 & 71.11 & 78.55 & 14.0 \\
\hline \multirow{2}{*}{7} & \multirow{2}{*}{ Meseret Christos high school } & \multirow{2}{*}{ May 18} & 9:00-11:00 AM & 85.90 & 69.90 & 2.85 & 82.50 & 89.91 & 16.0 \\
\hline & & & 15:00-17:00 PM & 83.50 & 69.70 & 2.56 & 76.36 & 82.91 & 13.8 \\
\hline \multirow[b]{2}{*}{8} & \multirow{2}{*}{ Bisrat High school } & \multirow{2}{*}{ May 19} & 9:00-11:00 AM & 82.00 & 64.50 & 2.96 & 73.75 & 81.34 & 17.5 \\
\hline & & & 15:00-17:00 PM & 84.5 & 68.9 & 3.80 & 76.44 & 86.18 & 15.6 \\
\hline \multirow{5}{*}{9} & \multirow{2}{*}{ Comprehensive high school } & \multirow{2}{*}{ May 20} & 9:00-11:00 AM & 89.56 & 70.4 & 3.16 & 83.50 & 91.58 & 19.2 \\
\hline & & & 15:00-17:00 PM & 87.06 & 72.66 & 3.90 & 82.26 & 92.24 & 14.4 \\
\hline & \multirow[t]{3}{*}{ Addis Hiwot high School } & May 21 & 9:00-11:00 AM & 73.10 & 54.82 & 5.22 & 67.93 & 81.30 & 18.3 \\
\hline & & & 15:00-17:00 PM & 72.3 & 52.1 & 2.78 & 61.05 & 68.16 & 20.2 \\
\hline & & May & 9:00-11:00 AM & 79.8 & 65.7 & 3.69 & 73.27 & 82.72 & 14.1 \\
\hline 10 & Alliance France School & & 15:00-17:00 PM & 82.77 & 68.5 & 2.79 & 79.32 & 86.47 & 14.3 \\
\hline
\end{tabular}




\subsection{The Noise Pollution Levels Around Hotels and Cafe}

Table 4 shows the noise levels and the degree of pollution around hotels. As we from the table the peak noise pollution were recorded in Aman Hotel No. 3, Yigezu Hotel, MA Hotels from 20:00 to 22:00 PM. In all hotels, the noise pollution observed in the morning and afternoon is almost the same. In the day time, the surrounding area is exposed by traffic noise but in afternoon or in the night time the surrounding area exposed by the noise produced by the amplifiers. This disturbs the life of the peoples around the place.

Table 4. Noise Levels in $\mathrm{dB}$, Noise Range, the equivalent noise levels and noise pollution Levels in near to Hotel and recreational areas in 2016.

\begin{tabular}{|c|c|c|c|c|c|c|c|c|c|}
\hline No & Place & Date & Time & $\operatorname{Max}(d B)$ & $\operatorname{Min}(d B)$ & Std & $\operatorname{Leq}(d B)$ & $\mathrm{LNP}(\mathrm{dB})$ & Range(dB) \\
\hline \multirow{2}{*}{1} & \multirow{2}{*}{ Aman Hotel (No. 3) } & \multirow{2}{*}{ May 13} & 9:00-11:00 AM & 99.3 & 77.3 & 5.87 & 93.70 & 103.3 & 22 \\
\hline & & & 20:00-22:05 PM & 96.8 & 74.5 & 5.00 & 90.48 & 108.73 & 22.3 \\
\hline \multirow{2}{*}{2} & \multirow{2}{*}{ Bridge Café } & \multirow{2}{*}{ June 9} & 9:00-11:00 AM & 90.62 & 70.6 & 3.85 & 86.98 & 96.83 & 20.02 \\
\hline & & & 20:00-22:00 PM & 94.36 & 80.2 & 2.82 & 90.92 & 98.14 & 14.16 \\
\hline \multirow{2}{*}{3} & \multirow{2}{*}{ Care Square } & \multirow{2}{*}{ June 10} & 9:00-11:00 AM & 66.40 & 50.41 & 4.29 & 60.84 & 71.81 & 15.99 \\
\hline & & & 20:00-22:00 PM & 92.8 & 78.5 & 4.15 & 87.53 & 98.16 & 14.3 \\
\hline 4 & Konel (Hashime) & June 11 & 9:00-11:00 AM & 91.53 & 79.8 & 2.53 & 88.20 & 94.69 & 11.73 \\
\hline \multirow{2}{*}{5} & \multirow{2}{*}{ Medirbabur club } & \multirow{2}{*}{ June 12} & 9:00-11:00 AM & 86.60 & 77.7 & 1.97 & 83.81 & 88.86 & 8.9 \\
\hline & & & 20:00-22:00 PM & 92.40 & 79.8 & 3.58 & 87.04 & 96.21 & 12.6 \\
\hline \multirow{2}{*}{6} & Mulugeta & \multirow{2}{*}{ June 13} & 9:00-11:00 AM & 89.9 & 78.9 & 2.33 & 85.79 & 91.76 & 11 \\
\hline & Hotel & & 20:00-22:00 PM & 96.9 & 80.68 & 4.79 & 92.57 & 92.57 & 16.22 \\
\hline \multirow{2}{*}{7} & \multirow{2}{*}{ Shemendefer hotel } & \multirow{2}{*}{ June 14} & 9:00-11:00 AM & 89.98 & 80.38 & 2.67 & 86.57 & 93.41 & 9.6 \\
\hline & & & 20:00-22:00 PM & 92.08 & 80.48 & 3.11 & 88.62 & 96.58 & 11.6 \\
\hline 8 & Yigezu Hotel & June 15 & 9:00-11:00 AM & 80.35 & 70.15 & 2.86 & 76.93 & 84.25 & 10.2 \\
\hline \multirow{2}{*}{9} & \multirow{2}{*}{ MA Hotel } & \multirow{2}{*}{ June 16} & 9:00-11:00 AM & 79.93 & 63.50 & 2.81 & 76.58 & 83.78 & 16.43 \\
\hline & & & 20:00-22:00 PM & 93.27 & 78.80 & 2.97 & 109.99 & 117.61 & 14.47 \\
\hline \multirow{2}{*}{10} & \multirow{2}{*}{ Orbit Hotel } & \multirow{2}{*}{ June 17} & 9:00-11:00 AM & 79.3 & 60.1 & 4.55 & 70.27 & 81.93 & 19.2 \\
\hline & & & 20:00-22:00 PM & 83.3 & 70 & 2.62 & 74.94 & 81.65 & 13.3 \\
\hline
\end{tabular}

\subsection{The Noise Pollution Levels Around Hospitals}

Offices in Dire Dawa city were other part of the survey shown in Table 5. Aweragodana, Bus Station, Medir Babur, Sabian police, Kebele 02, Tele office, Finance, United Nation World Food Program (UNWFP), Oxyde store, Airlines ticket office, Dire Dawa educational Bureau, Commercial bank and Agricultural offices were considered. The highest recorded sound level in Leq and LNP recorded was $95.89 \mathrm{~dB}$ and 104.6 dB around Medirbabur between 9:00 and 11:00 AM time period and the minimum was recorded at Oxyde which was $56.03 \mathrm{~dB}$ and $74.41 \mathrm{~dB}$ respectively. The offices like Post office, Dashen Bank, Education Bureau and other found on this area were affected because of the volume of the traffic and interaction of the road with the tyre. This affects the motivation of workers to do their tasks efficiently.

Table 5. Noise Levels in dB, Noise Range, the equivalent noise levels and noise pollution Levels in neat to City Offices in 2016.

\begin{tabular}{|c|c|c|c|c|c|c|c|c|c|}
\hline No & Place & Date & Time & $\operatorname{Max}(d B)$ & $\operatorname{Min}(d B)$ & Std & $\operatorname{Leq}(\mathrm{dB})$ & $\operatorname{LNP}(d B)$ & Range(dB) \\
\hline \multirow{2}{*}{1} & \multirow{2}{*}{ Aweragodana } & \multirow{2}{*}{ June 18} & 9:00-11:00 AM & 87.8 & 75.57 & 3.23 & 84.08 & 92.37 & 12.23 \\
\hline & & & 18:00-20:00 PM & 86.62 & 74.42 & 3.25 & 83.07 & 91.41 & 12.2 \\
\hline \multirow{2}{*}{2} & \multirow{2}{*}{ Bus Station } & \multirow{2}{*}{ June 19} & 6:00-8:00 AM & 90.5 & 78.65 & 3.40 & 86.89 & 95.61 & 11.85 \\
\hline & & & 16:00-18:00 PM & 92.06 & 84.26 & 2.23 & 89.10 & 94.81 & 7.8 \\
\hline \multirow{2}{*}{3} & \multirow{2}{*}{ Medirbabur } & \multirow{2}{*}{ June 20} & 9:00-11:00 AM & 100 & 87.3 & 3.40 & 95.89 & 104.60 & 12.7 \\
\hline & & & 18:05-20:00 PM & 93.51 & 85.21 & 2.34 & 90.41 & 96.41 & 8.3 \\
\hline \multirow{2}{*}{4} & \multirow{2}{*}{ Sabian Police Tabeiya } & \multirow{2}{*}{ June 21} & 9:00-11:00 AM & 89.6 & 79.56 & 3.02 & 86.14 & 93.88 & 10.04 \\
\hline & & & 18:00-20:00 PM & 89.81 & 76.7 & 2.41 & 86.77 & 92.94 & 13.11 \\
\hline \multirow{2}{*}{5} & \multirow{2}{*}{ Kebele 02 Office } & \multirow{2}{*}{ June 22} & 9:00-11:00 AM & 82.50 & 65.36 & 2.99 & 76.55 & 84.22 & 17.14 \\
\hline & & & 15:00-17:00 PM & 78.50 & 69.03 & 2.49 & 75.07 & 81.45 & 9.47 \\
\hline \multirow{2}{*}{6} & \multirow{2}{*}{ Tele Office } & \multirow{2}{*}{ June 23} & 9:00-11:00 AM & 82.40 & 70.42 & 3.25 & 77.46 & 85.79 & 11.98 \\
\hline & & & 15:00-17:00 PM & 78.33 & 68.40 & 2.27 & 74.60 & 80.42 & 9.93 \\
\hline \multirow{2}{*}{7} & \multirow{2}{*}{ Finance Office } & \multirow{2}{*}{ June 24} & 9:00-11:00 AM & 82.60 & 69.90 & 3.78 & 78.91 & 88.61 & 12.7 \\
\hline & & & $15: 00-17: 00 \mathrm{PM}$ & 79.33 & 70.18 & 2.63 & 76.16 & 82.90 & 9.15 \\
\hline \multirow{2}{*}{8} & \multirow{2}{*}{ UNWFP Office } & \multirow{2}{*}{ June 25} & 9:00-11:00 AM & 78.50 & 65.40 & 2.02 & 74.31 & 79.49 & 13.1 \\
\hline & & & $15: 00-17: 00 \mathrm{PM}$ & 71.50 & 56.45 & 3.60 & 66.30 & 75.52 & 15.05 \\
\hline \multirow{2}{*}{9} & \multirow{2}{*}{ Oxyde Store } & \multirow{2}{*}{ June 26} & 9:00-11:00 AM & 89.5 & 74.75 & 3.41 & 82.97 & 91.72 & 14.75 \\
\hline & & & $15: 00-17: 00 \mathrm{PM}$ & 69.5 & 56.08 & 3.54 & 65.33 & 74.41 & 13.42 \\
\hline \multirow{2}{*}{10} & \multirow{2}{*}{ Air lines Office } & \multirow{2}{*}{ June 27} & 9:00-11:00 AM & 77.9 & 67 & 2.29 & 74.84 & 80.71 & 10.9 \\
\hline & & & $15: 00-17: 00 \mathrm{PM}$ & 80.2 & 70.53 & 2.65 & 77.00 & 83.79 & 9.67 \\
\hline
\end{tabular}




\begin{tabular}{|c|c|c|c|c|c|c|c|c|c|}
\hline No & Place & Date & Time & $\operatorname{Max}(\mathrm{dB})$ & $\operatorname{Min}(\mathrm{dB})$ & Std & $\operatorname{Leq}(d B)$ & LNP(dB) & Range(dB) \\
\hline \multirow{2}{*}{11} & \multirow{2}{*}{ Dire-Dawa Education Bureau } & \multirow{2}{*}{ June 28} & 9:00-11:00 AM & 79.94 & 62.40 & 3.04 & 76.74 & 84.55 & 17.54 \\
\hline & & & 15:00-17:00 PM & 76.78 & 66.13 & 2.95 & 73.50 & 81.08 & 10.65 \\
\hline \multirow{4}{*}{12} & \multirow{2}{*}{ Commercial Bank } & \multirow{2}{*}{ June 29} & 9:00-11:00 AM & 79.50 & 69.9 & 2.16 & 76.44 & 81.98 & 9.6 \\
\hline & & & 15:00-17:00 PM & 78.2 & 64.8 & 1.28 & 70.51 & 73.81 & 13.4 \\
\hline & \multirow{2}{*}{ Dire-Dawa Agricultural Office } & \multirow{2}{*}{ June 30} & 9:00-11:00 AM & 84.2 & 69.87 & 3.02 & 77.12 & 84.86 & 14.33 \\
\hline & & & 15:00-17:00 PM & 74.3 & 61.5 & 2.28 & 71.12 & 76.97 & \\
\hline
\end{tabular}

\subsection{The Noise Pollution Levels Around Residence}

The residence places which are taken as residence in the city for this study was Gendekore, Haftesa, Megala, Papa, Shell, Police meret, Legehare, Goro-hadid, bargelle, Jerba and GendeLome villages shown in Table 6. In these areas comparably there was variation of noise pollution levels to each other. These areas include business and residential places. The maximum record in sound level, Leq, LNP around Shell was $94.06,90.91 \mathrm{~dB}$ and $97.23 \mathrm{~dB}$ respectively in time interval of 9:00 - 11:00 AM. While the minimum record in sound level, Leq, LNP around Bargelle village was $42.20,45.72 \mathrm{~dB}$ and $48.50 \mathrm{~dB}$ respectively in time interval 18:00 - 20:00 PM. Accordingly, Bargelle is some-what good place for the residence than the other places.

Table 6. Noise Levels in dB, Noise Range, the equivalent noise levels and noise pollution Levels in near to the Residence sites in 2016.

\begin{tabular}{|c|c|c|c|c|c|c|c|c|c|}
\hline No & Place & Date & Time & $\operatorname{Max}(d B)$ & $\operatorname{Min}(\mathrm{dB})$ & Std & $\operatorname{Leq}(d B)$ & $\mathrm{LNP}(\mathrm{dB})$ & Range(dB) \\
\hline \multirow{2}{*}{1} & \multirow{2}{*}{ Gende Kore } & \multirow{2}{*}{ June 31} & 9:00-11:00 AM & 79.93 & 64.5 & 2.80 & 76.63 & 83.82 & 15.43 \\
\hline & & & 18:00-20:00 PM & 71.2 & 58.76 & 2.51 & 67.95 & 74.38 & 12.44 \\
\hline \multirow{2}{*}{2} & \multirow{2}{*}{ Haftesa } & \multirow{2}{*}{ July 1} & 9:00-11:00 AM & 84.6 & 70.5 & 3.05 & 80.99 & 88.80 & 14.1 \\
\hline & & & 18:00-20:00 PM & 82.4 & 62.1 & 2.49 & 70.64 & 77.03 & 20.3 \\
\hline \multirow{2}{*}{3} & \multirow{2}{*}{ Megala } & \multirow{2}{*}{ July 2} & 9:00-11:00 AM & 93.6 & 62.1 & 3.83 & 74.52 & 84.35 & 31.5 \\
\hline & & & 18:00-20:00 PM & 79.7 & 60.11 & 3.70 & 67.38 & 76.87 & 19.59 \\
\hline 4 & Papa & July 3 & 9:00-11:00 AM & 89.61 & 80.5 & 2.35 & 86.51 & 92.52 & 9.11 \\
\hline \multirow{2}{*}{5} & \multirow{2}{*}{ Shell } & \multirow{2}{*}{ July 4} & 9:00-11:00 AM & 89.5 & 78.5 & 2.53 & 86.07 & 92.55 & 11 \\
\hline & & & $15: 00-17: 00$ PM & 94.06 & 84.76 & 2.46 & 90.91 & 97.23 & 9.3 \\
\hline \multirow{2}{*}{6} & \multirow{2}{*}{ Police Meret } & \multirow{2}{*}{ July 5} & 9:00-11:00 AM & 81.50 & 73.40 & 1.86 & 77.87 & 82.65 & 8.1 \\
\hline & & & 18:00-20:00 PM & 86.96 & 80.12 & 1.95 & 84.13 & 89.14 & 6.84 \\
\hline \multirow{2}{*}{7} & \multirow{2}{*}{ Legehare road } & \multirow{2}{*}{ July 6} & 9:00-11:00 AM & 84.50 & 80.50 & 0.44 & 82.64 & 83.78 & 4 \\
\hline & & & 18:00-20:00 PM & 83.20 & 60.30 & 1.78 & 68.03 & 72.61 & 22.9 \\
\hline \multirow{2}{*}{8} & \multirow{2}{*}{ Number one } & \multirow{2}{*}{ July 7} & 9:00-11:00 AM & 79.00 & 75.60 & 0.47 & 77.94 & 79.16 & 3.4 \\
\hline & & & $18: 00-20: 00$ PM & 58.90 & 55.40 & 0.44 & 57.91 & 59.05 & 3.5 \\
\hline 9 & Goro-Hadid & July 8 & 18:00-20:00 PM & 53.4 & 47.7 & 0.59 & 50.76 & 52.28 & 5.7 \\
\hline \multirow{2}{*}{10} & \multirow{2}{*}{ bargelle } & \multirow{2}{*}{ July 9} & 9:00-11:00 AM & 49.70 & 44.50 & 0.57 & 47.87 & 49.33 & 5.2 \\
\hline & & & 18:00-20:00 PM & 53.40 & 42.20 & 1.08 & 45.72 & 48.50 & 11.2 \\
\hline \multirow{2}{*}{11} & \multirow{2}{*}{ jerba } & & 9:00-11:00 AM & 84.50 & 78.60 & 0.58 & 82.00 & 83.50 & 5.9 \\
\hline & & July 10 & 18:00-20:00 PM & 62.30 & 43.90 & 3.56 & 51.46 & 60.57 & 18.4 \\
\hline 12 & Gende I ome & Iuly 11 & 9:00-11:00 AM & 62.30 & 43.90 & 3.56 & 51.46 & 60.57 & 18.4 \\
\hline 12 & Gende Lome & July 11 & 18:00-20:00 PM & 53.40 & 42.20 & 1.08 & 45.72 & 48.50 & 11.2 \\
\hline
\end{tabular}

\section{Conclusions and Recommendations}

\subsection{Conclusions}

Noise pollution, noise levels and average of noise levels were calculated using the data collected for two months (morning and afternoon) in 2016 in selected area of DireDawa city Administrations. The following are concluded from this research work. The noise level data were collected near to the hospitals, schools, offices, churches and mosques and offices and hotels were escalating at very fast rate with growing population and heavy traffic accumulation. The types of road we have around the city have also contribution for rise of noise levels in the city. In many parts of the area of the study the noise pollution level reached as high as $86 \mathrm{~dB}$ estimated by [18]. Dire-Dawa city administration is suffering from severe noise pollution due to vehicles traffic and it seems the authorities are less concerned about the increase in noise pollutions levels throughout the city. The administrator should design strategic plan to reduce noise pollution from schools, hospitals, offices, churches, mosques and residence place in order to a good citizens' to perform their daily duties or tasks properly.

\subsection{Recommendations}

We recommended the following main points based this research outputs for action should be taken the concerned body.

- Noise protection programs legal frames should be designed by the city administration to protect the residence.

- The industry sites, highways and airports should be far from the residential areas.

- Handling the compliance/ non-compliance noise sources according to the regulations that will be set by 
the city administration.

- Have health control require mitigation of noise emissions, and not just of noise source emissions. The following should be taken into considerations

- Specific environments such as schools, residence, hospitals and offices

- Environments with multiple noise sources or which amplify its effects

- Introduces surveillance systems for noise-related adverse health effects.

- Adopt guidelines for community noise as intermediary targets for improving citizens' health.

- Create awareness for the society by organizing workshop

- Further investigations should be done with experts on this area in collaboration with Dire-Dawa University.

\section{Acknowledgment}

This work is supported by Dire-Dawa University. We thank the Directorate of Research and Technology Interchange for the grant and it is a great pleasure to thank Dr. Ephrem Mengistu for his valuable suggestions and comments to improve the quality of this paper.

\section{References}

[1] Durduran S. S., Kunt F., and Dursun S., 2008. "Noise mapping in Konya (Turkey) city hospitals using GIS model." Journal of International Environmental Applications and Science, Vol 3 (5): 415-421.

[2] Cuniff, P. F. Environmental Noise Pollution. University of Maryland, John Wiley \& sons. Declan, B. (2004). Noise management: Sound and vision, Nature 427, (1977), 480-481.

[3] Bruel and Kjaer, 2002 "Environmental noise. Denmark.: http://www.bksv.com/pdf/Environmental\%20Booklet.pdf, Access date 25-09.06.

[4] WHO, 1999 "Guidelines for Community Noise" http://www.ruidos.org/Noise/WHO_Noise_guidlines _contents.html, Access date: 15-11-06.

[5] Wawa E. A. and Mulaku, G. C. 2015. Noise Pollution Mapping Using GIS in Nairobi, Kenya. Journal of Geographic Information System, 7, 486-493. http://dx.doi.org/10.4236/jgis.2015.75039.

[6] Joshi N. A., Joshi C. N and Rane P. P;., 2015, Noise Mapping in Mumbai City, India. International Journal of Innovative Science, Engineering \& Technology, Vol. 2 Issue 3.

[7] Tandel B. N., and Tiwari K., 2013 "A GIS based approach for mapping of Urban noise".

[8] Karthik K., Paratheeban P., PrassadRaju H., and Anuradha P., 2015 "Development of Noise Predication Model Using GIS for Chennai City."International Journal of Emerging Technology and Advanced Engineering. Vol. 5. No. 10.

[9] Anirban K. C., AnupamDeb S., and Shibnath C., 2012, "Analysis of Day time traffic noise level: A case study of Kolkata, India." International Journal of Environmental Science Research. Vol 2. No. 2 pp 114-118.

[10] Cohen S., Evans G. W., Krantz D. Z., Stokols D., 1980. "Physiological, Motivational, and cognitive effects of aircraft noise on children. American Psychologist 35:231-243.

[11] Evans G. W., and Lepore S. J., 1993. "Non-auditory effects of noise on children": A critical review, children's Environmental 10: 31-35.

[12] Evans G. W., 1988. "Motivational consequences of exposure to noise" In N. L. Carter and R. F. S. Job (eds). Noise as a public Health Problem (Noise Effects '98), Vol. 1, p. 311-320. Noise effects '98 PTY Ltd., Sydney, Australia.

[13] Hygge S., Jones D. M., and Smith A. P., 1988 "Recent developments in noise and performance." In N. L., Carter and R. F. S. Job (eds). Noise as Noise as a public Health Problem (Noise Effects '98), Vol. 1, p. 311-320. Noise Effects '98 PTY Ltd., Sydney, Australia.

[14] Haines F. L., Stansfeld S. A., Job R. F. S., Berglund B., 1988. "Chronic aircraft noise exposure and child cognitive performance and stress." In N. L., Carter and R. F. S. Job (eds). Noise as Noise as a public Health Problem (Noise Effects '98), Vol. 1, p. 311-320. Noise Effects '98 PTY Ltd., Sydney, Australia.

[15] Omokhadion F. O., Ekanem S. U., and Uchendu O. C., 2008, Noise levels and hearing impairment in an urban Ibadan, Southwest, Nigeria, Journal of Public Health 16:399-402.

[16] Osuntogun B., 2006, Environmental impacts of urban road transport in South Western States of Nigeria. Available from www.iseg.giees. edu/abuja2006/Abstracts/Abstract_ID_214.pdf. uacc.

17] Berglund B., Lindvall T., and Schwela D. H., 1995. "Guidelines for Community noise" WHO, London, United Kingdom.

[18] King E. A., and Rice H. J., 2009. "The development of a practical framework for strategic noise mapping." Dublin, Ireland, Applied Acoustics 70, pp. 1116-1127. 